\title{
Carbohydrate restriction for diabetes: rediscovering centuries-old wisdom
}

\author{
Belinda S. Lennerz, ${ }^{1,2,3}$ Andrew P. Koutnik, ${ }^{4,5}$ Svetlana Azova, ${ }^{1,2,3}$ Joseph I. Wolfsdorf, ${ }^{2,3}$ and David S. Ludwig ${ }^{1,2,3}$ \\ ${ }^{1}$ New Balance Foundation Obesity Prevention Center, Boston Children's Hospital, and ²Division of Endocrinology, Boston Children's Hospital, Boston, Massachusetts, USA. ${ }^{2}$ Department of Pediatrics, \\ Harvard Medical School, Boston, Massachusetts, USA. ${ }^{4}$ Human Health, Resilience \& Performance, Institute for Human and Machine Cognition, and ${ }^{5}$ Department of Molecular Pharmacology and Physiology, \\ University of South Florida, Tampa, Florida, USA
}

\begin{abstract}
Carbohydrate restriction, used since the 1700 s to prolong survival in people with diabetes, fell out of favor after the discovery of insulin. Despite costly pharmacological and technological developments in the last few decades, current therapies do not achieve optimal outcomes, and most people with diabetes remain at high risk for micro- and macrovascular complications. Recently, low-carbohydrate diets have regained popularity, with preliminary evidence of benefit for body weight, postprandial hyperglycemia, hyperinsulinemia, and other cardiometabolic risk factors in type 2 diabetes and, with more limited data, in type 1 diabetes. High-quality, long-term trials are needed to assess safety concerns and determine whether this old dietary approach might help people with diabetes attain clinical targets more effectively, and at a lower cost, than conventional treatment.
\end{abstract}

\section{Introduction}

The primary goal of medical nutrition therapy (MNT) for diabetes management is to achieve optimal metabolic control - blood glucose (BG) levels in the normal range, or as near normal as safely possible, and lipid levels in the recommended ranges - to reduce the risk of micro- and macrovascular complications, while preserving normal growth and development in the case of children $(1,2)$. Increasing recognition of the contribution of postprandial hyperglycemia to elevated glycated hemoglobin (HbA1c) levels and as an independent risk factor for diabetes complications (3) highlights the importance of reducing glycemic excursions (4). As the principal determinant of postprandial glycemia, dietary carbohydrate offers an attractive therapeutic target.

Qualitative aspects of carbohydrate (e.g., fiber) are universally emphasized in nutrition guidelines. However, carbohydrate reduction can decrease postprandial glycemia and insulin requirements more effectively than any other dietary intervention, with additional benefits for reducing cardiometabolic risk factors (5). Nevertheless, concern for hypoglycemia, ketoacidosis, nutritional insufficiency, poor growth in children, and long-term acceptability has limited the adoption of low-carbohydrate diets in diabetes. In this Review, we provide a historical overview of MNT and examine research on carbohydrate-modified diets, with particular emphasis on type 1 diabetes (T1D).

Conflict of interest: DSL received royalties for books on obesity and nutrition that recommend a low-glycemic load diet and philanthropic grants from the New Balance Foundation and Arnold Ventures. APK is an inventor on provisional patent applications related to the use of exogenous ketone bodies (US patents 16/768,242, 16/772,490, 16/998,281, and 62/964,952; European patent 18888960.4). JIW received royalties for his role as a section editor for UpToDate.

Copyright: () 2021, American Society for Clinical Investigation.

Reference information: / Clin Invest. 2021;131(1):e142246.

https://doi.org/10.1172/JCl142246.

\section{History of carbohydrate recommendations} for diabetes

\section{The preinsulin era}

Before the discovery of insulin, carbohydrate restriction prolonged the lives of people with diabetes. In 1797, Rollo prescribed a diet of moderation, consisting largely of meat and fat, based on observations that plant foods were associated with glucosuria (6). This prescription was widely adopted and empirically optimized over the next century. While Rollo and others promoted fat intake to mitigate nausea and anorexia, diets were often high in protein (e.g., $3 \mathrm{~g} / \mathrm{kg}$ body weight or $43 \%$ of energy intake [EI], according to a "fair example" described by Woodyatt) (7).

Physiological experimentation and clinical experience subsequently led to variations of the carbohydrate-restricted diet. In the late 19th century, Cantani and Naunyn first described the effects of protein intake on glucose levels and advocated restriction of both carbohydrate and protein to treat glucosuria. With this approach, dietary fat was used to satisfy most energy requirements (8), and, according to a contemporaneous review, up to about $200 \mathrm{~g} / \mathrm{d}$ was considered well tolerated (9). Based on animal studies and observations that intake of fat and protein exacerbated ketonuria during ketoacidosis, Allen and Joslin introduced prolonged fasting and hypocaloric diets that restricted all macronutrients (10-12). Although effective in treating ketoacidosis, Allen's prescription amounted to a starvation diet that produced severe side effects and fatalities in some cases (13). To prevent inanition, Newburgh and Marsh developed diets with exceptionally high fat content (EI $\sim 5 \%$ carbohydrate, $8 \%$ protein, and $87 \%$ fat) that prolonged life (14) compared with the contemporary high mortality within the first year of diabetes diagnosis $(12,15)$. Other clinicians reported success with ostensibly higher-carbohydrate diets, such as the "rice cure" or "oatmeal cure," that still provided lower relative and absolute amounts of glucose and gluconeogenic substrates than 
were conventionally consumed because of their hypocaloric and protein-restricted nature and the inclusion of fat (7).

Aiming to reconcile nutritional controversies, Woodyatt explored the contributions of endogenous fuels to metabolism in the 1920s, demonstrating that patients with diabetes and obesity did well on calorie-restricted diets, but those with undernutrition experienced loss of lean mass. This catabolic process not only produced inanition, but also released large amounts of amino acids from muscle that fueled gluconeogenesis and ketogenesis, exacerbating glucosuria and acidosis. In further experiments, Woodyatt, among others, found that both glucosuria and acidosis could be prevented by increasing dietary fat to preserve endogenous fat stores (7), and Wilder noted that a certain degree of ketosis was well tolerated (16), laying the foundation for differentiating nutritional ketosis from ketoacidosis (see "Carbohydrate amount" below). With the discovery of insulin in 1921, however, this line of research was largely abandoned.

\section{Early insulin era}

Insulin was initially used as an adjunct to prevailing diets that restricted carbohydrate and promoted a mild energy deficit. By the 1940s, diets with higher carbohydrate content gained favor, with reports of increased energy level, less hunger (potentially related to higher total EI), and better compliance (17). At that time, lacking practical methods for frequent monitoring, BG was measured infrequently and primarily in the fasting state; thus, the impact of high-carbohydrate diets on insulin needs and postprandial glycemia was mostly unrecognized $(18,19)$. Moreover, studies published during this time, such as by Himsworth (20), suggested a benefit of higher carbohydrate consumption for glucose tolerance and insulin sensitivity in people without diabetes, supporting the notion that additional carbohydrate intake would not increase insulin requirement $(18,19)$. Possibly owing to a lack of appreciation for the difference between nutritional ketosis and ketoacidosis - and despite earlier findings on this point $(16,21)$ - many clinicians prioritized reducing ketonuria over the glucosuria that occurred with higher-carbohydrate diets (18). Moreover, some pediatricians specifically aimed for glucosuria and accepted any degree of hyperglycemia to lower the risk of "reactions" (hypoglycemia), provided that the patient felt well and did not lose weight (22).

An additional rationale for a higher-carbohydrate diet was its effect on lowering blood cholesterol. By the 1930s, dietary and blood cholesterol had been linked to cardiovascular disease (CVD) in the general population (23), whereas the relationship between glycemia and diabetic complications was not fully accepted until publication of the results of the Diabetes Control and Complications Trial (DCCT) more than a half century later (24). Hence, focus on diabetes research shifted toward lower-fat, high-carbohydrate diets that lowered cholesterol levels (25-27). More broadly, the notion developed that as glucose levels could be controlled by insulin replacement, the nutritional needs of people with diabetes would mirror those of healthy individuals, and subsequent dietary recommendations largely paralleled those for the general population.

Nevertheless, throughout this period, controversy persisted regarding optimal dietary composition. In 1932, Strouse reported increased glucosuria and higher insulin requirements on iso- caloric high-carbohydrate (65\% EI) versus low-carbohydrate (9\% EI) diets (28). In the 1960s, Bierman linked higher carbohydrate intake to elevated triglyceride levels in diabetes (29), which Albrink considered a risk factor for micro- and macrovascular complications, even as she questioned the importance of total serum cholesterol (30). In addition, animal studies suggested unique metabolic benefits of carbohydrate restriction. Rodents with experimental diabetes (induced by subtotal pancreatectomy) self-selected a low-carbohydrate diet and had spontaneous resolution of polydipsia, polyphagia, and weight loss $(31,32)$.

\section{Evolution of modern ADA dietary guidelines}

The first American Diabetes Association (ADA) guidelines in 1971 (33) acknowledged that "there are no controlled prospective studies which provide evidence for choosing the optimal proportion of dietary carbohydrate and fat with regard to long-term complications in any type of diabetic population." Despite these "obvious important knowledge [gaps]," the guidelines suggested that carbohydrate intake of $45 \% \mathrm{EI}$, based on population norms, or higher "appears to be acceptable" for the usual patient, while also raising concern for carbohydrate-associated hypertriglyceridemia. With advances in monitoring of glycemia during the decade, the 1979 ADA guidelines (34) revised the goals of dietary management from avoiding "deleterious metabolic derangements" (33) to maintaining "plasma glucose as near to the normal physiologic range as possible."

By that time, most public health nutrition experts had come to advocate a low-fat, high-carbohydrate diet for weight control and chronic disease prevention (35) in the general population, with research on diabetes shifting to qualitative aspects of carbohydrate, such as fiber and, later, glycemic index (GI) (36-38). High carbohydrate intake (50\%-60\% EI) was recommended, not only for the presumed benefits of high-fiber foods, but also to help limit saturated fat intake. In the 1986 ADA guidelines (39), total fat intake was explicitly restricted to $<30 \% \mathrm{EI}$, and carbohydrate amount was "liberalized, ideally up to $55-60 \%$ of the total calories."

In 1993, the DCCT showed that intensive diabetes management that achieved near-normal glycemic control reduces the risk of microvascular complications. Intensively treated participants in the DCCT received MNT that focused on carbohydrate consistency and adjustment of insulin doses for variations in dietary intake $(24,40,41)$. The following year (42), the ADA abandoned specific targets for dietary carbohydrate, recognizing a lack of supporting data, and instead encouraged an individualized approach focused on qualitative dietary aspects. Even so, advice to limit fat intake was maintained, based on recommendations for the general population.

The GI (a measure of the glycemic effects of food, as considered below) (38) was first addressed by the ADA in 2002 (43); in 2006 (44), it concluded that use of GI may provide a modest benefit, beyond consideration of carbohydrate amount alone. This latter report cautioned that "foods that contain carbohydrate are important sources of energy, fiber, vitamins, and minerals and are important in dietary palatability" and advised against intakes less than the prevailing recommended daily allowance $(130 \mathrm{~g} / \mathrm{d})$, while again noting a lack of diabetes-specific data. The 2014 ADA guidelines (45) stated that "there is not an ideal percentage of calories 


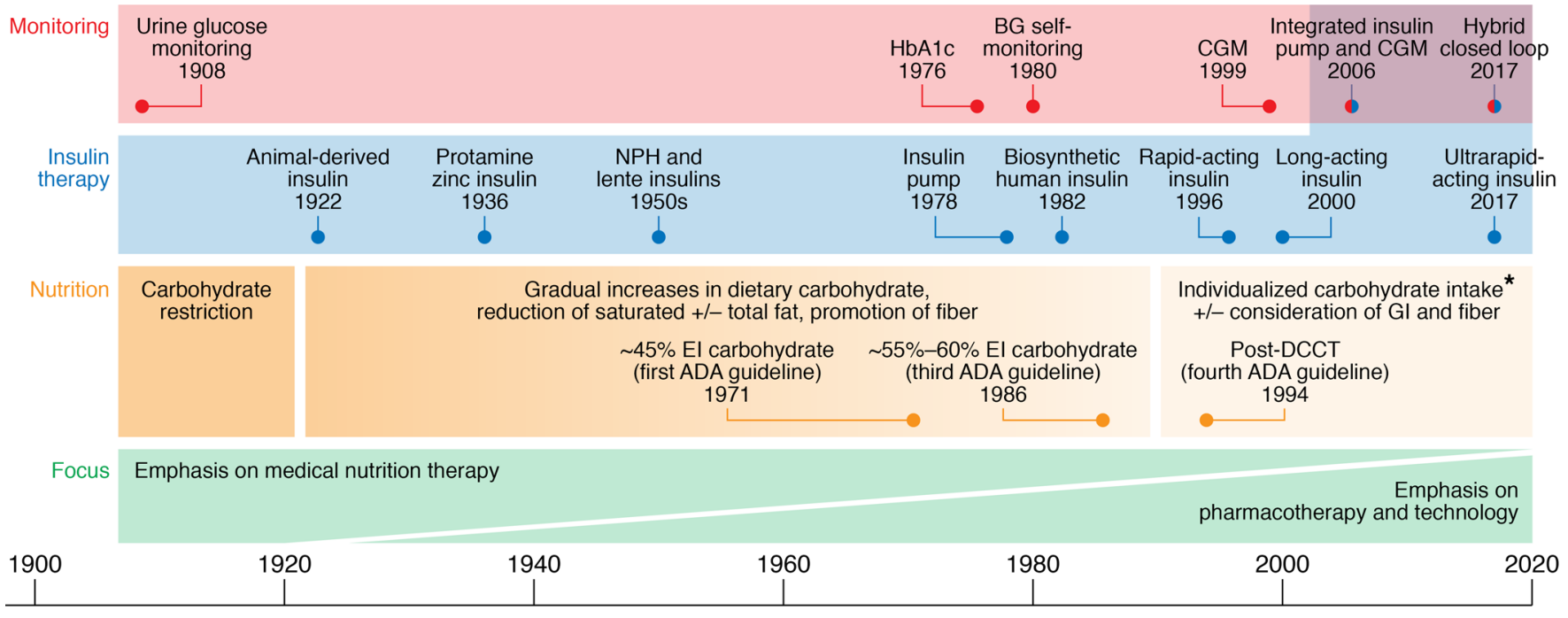

Figure 1. Hundred-year timeline of dietary recommendations and technological developments for diabetes. During the 100 years since the discovery of insulin, the focus of research and clinical care has shifted from nutrition to improving insulin formulations, glucose monitoring, and insulin delivery technology. ADA, American Diabetes Association; BC, blood glucose; CGM, continuous glucose monitoring; DCCT, Diabetes Control and Complications Trial; El, energy intake; GI, glycemic index. *Other guidelines still maintain high-carbohydrate recommendations.

from carbohydrate, protein, and fat for all people with diabetes," language that was essentially retained in the 2019 guidelines (46), with the new acknowledgment that for "people with type 2 diabetes or prediabetes, low-carbohydrate eating plans show potential to improve glycemia and lipid outcomes for up to 1 year." Other influential guidelines, such as those from the International Society for Pediatric and Adolescent Diabetes, continue to promote high intakes of carbohydrate ( $45 \%-50 \%$ EI) and specifically caution against low-carbohydrate diets in children and adolescents (47).

\section{Trends in glycemic control amid technological developments}

In the last 50 years, major pharmacological and technological innovations have been developed to improve glycemic control (Figure 1), including insulin analogs and insulin delivery systems, providing major benefits, but at substantial expense to patients and the health care system.

Self-monitoring of BG allowed patients to make daily therapeutic decisions and to have glycemic targets (48), a prerequisite for intensive insulin therapy with flexible dietary prescriptions (49); however, this method also introduced new challenges. In current "carbohydrate counting" approaches, patients adjust premeal insulin doses to match planned carbohydrate intake (50) and add insulin if BG is above target. Patients must have access to comprehensive nutrition education and the cognitive development and numeracy skills to accurately estimate the carbohydrate content of food (51). Studies have shown wide variations in the ability to accurately count carbohydrates (52-54). Postprandial glycemia and insulin requirements are also affected by carbohydrate quality (i.e., GI) and intake of other macronutrients (55-58), in addition to factors unrelated to diet, such as exercise. Protein contributes to postprandial glycemia and insulin requirements by providing amino acid substrates for gluconeogenesis (59) and by stimulating glucagon secretion $(60,61)$. Dietary fat delays gastric emptying, blunts the early rise in plasma glucose, and causes dose-depen- dent late postprandial hyperglycemia $(62,63)$. Because of the obvious complexity of these interactions, only select individuals are able to master mealtime insulin adjustment to account for variations in the macronutrient composition of usual diets.

Rapid- and ultrarapid-acting insulin analogs, with their earlier onset and shorter duration of action (2) compared with regular insulin, have allowed for more physiological coverage of carbohydrate intake. Despite their rapid absorption, the action of insulin analogs peaks after 90-120 minutes and persists for 5-6 hours (64). In contrast, glucose appearance in blood from a mixed meal typically peaks within 60 minutes and persists only 2-3 hours (65), a mismatch that can be partially addressed by administration of insulin 15-20 minutes before the start of the meal $(4,66)$. However, glycemic response to high-carbohydrate meals varies substantially among individuals, even with careful control of other dietary factors, and prevention of both early prandial hyperglycemia and late postprandial hypoglycemia remains a major challenge (67).

Continuous glucose monitoring (CGM) systems provide detailed information on glucose patterns and have the additional advantage of showing the direction and rate of change of glucose concentrations (68). CGM can enable patients to observe how food factors affect their postprandial glucose profiles, allowing them to more precisely match insulin delivery to the size and macronutrient content of the meal. Coupling insulin pumps with CGM, hybrid closed-loop (HCL) systems automatically modulate insulin delivery to counteract glycemic trends toward hypo- or hyperglycemia. However, because of the aforementioned mismatch in carbohydrate absorption rate and insulin pharmacodynamics, this approach does not eliminate the need for premeal bolusing.

Together, these developments have translated into greater convenience and flexibility for patients. Epidemiologic and comparative studies have shown clinically meaningful HbA1c reductions of about $1 \%-2 \%$ with intensive insulin therapy $(24,69)$ (although with substantial variance based on patients' abilities; 
ref. 70$), 0.8 \%-1.3 \%$ with combined pump and CGM use (71), and an additional $\sim 0.3 \%$ with HCL (72). Nevertheless, glycemic control in the United States remains suboptimal. A recent report from the Type 1 Diabetes Exchange Registry showed that only $17 \%$ of children and $20 \%$ of adults achieve the glycemic targets of $<7.5 \%$ and $<7 \%$, respectively (71). Furthermore, over the past decade, glycemic control in adolescents has deteriorated (71). Similarly, a substantial proportion of people with type 2 diabetes (T2D) fail to achieve glycemic and metabolic management goals, despite rapidly rising health care expenditures for diabetes $(73,74)$. Moreover, cardiovascular mortality and all-cause mortality among people with both forms of diabetes remain substantially higher than those in the general population $(75,76)$.

\section{Revisiting carbohydrate recommendations}

\section{Rationale}

Dietary carbohydrate, as the only macronutrient directly digested into glucose, is the main determinant of postprandial glycemia and insulin requirements (77-79). For most processed grains and other foods high in glycemic load (GL; the multiplicative product of GI and amount of digestible carbohydrate consumed), the digestion rate is exceptionally fast, increasing immediate insulin demand (80-82) and exacerbating the aforementioned mismatch between insulin kinetics and glucose appearance. Beyond glycemic control, a high-GL diet may also increase risk for cardiometabolic complications of diabetes (83-85), exacerbated by higher associated insulin requirements. Insulin resistance and hyperinsulinemia are well-recognized features common to both T2D and the metabolic syndrome (including central adiposity, hypertriglyceridemia, low HDL-cholesterol, hypertension, fatty liver, coagulopathy, and chronic inflammation) (86). Hyperinsulinemia is also characteristic of T1D, in part because the peripheral route of insulin administration (versus portal secretion) requires higher-than-normal systemic concentrations to control hepatic glucose output. Peripheral hyperinsulinemia increases anabolic activity of adipose tissue, potentially contributing to the higher incidence of overweight (71, 87) and metabolic syndrome in T1D (88-90). Although intensive insulin management on a conventional diet reduces postprandial hyperglycemia, weight gain frequently occurs (91-94) and is related to decreased glucosuria, increased calorie intake from treatment of more frequent hypoglycemia, and metabolic effects of hyperinsulinemia. Hence, measures to slow the rate (with a focus on carbohydrate quality) or total amount (low-carbohydrate diet) of glucose absorption from a meal may not only improve management of glycemia, but also reduce cardiometabolic risk. A reduction in GL may also help prevent T2D, in light of strong positive associations observed between high-GL foods (sugary beverages, processed grains, potatoes) (95-97) or an overall high-GL diet (98) and incidence of $\mathrm{T} 2 \mathrm{D}$ in prospective studies.

\section{Carbohydrate quality}

Independent of amount consumed, qualitative aspects of carbohydrate may influence glycemic control, metabolic responses, and CVD risk factors. Both soluble and insoluble fiber may affect the glycemic response to a meal, the former by increasing intraluminal viscosity in the small intestine and slowing carbohydrate absorption and the latter primarily through mechanical effects that slow digestion of intact foods (e.g., with whole-kernel but not highly refined grains). Dietary fiber may also promote insulin sensitivity through effects on the gut microbiome, production of short-chain fatty acids, and other actions (99). In a metaanalysis of 42 intervention trials and two prospective studies, highfiber versus control diets slightly reduced HbA1c (mean difference $-0.18 \%$ ) in patients with diabetes and showed small benefits for other measures of glycemia, serum lipids, body weight, and C-reactive protein levels (100). With regard to T1D, some studies have shown improvement in glycemic control (101-103), cholesterol levels (101), and inflammation (104), and reduction in allcause mortality and CVD (105), whereas others did not observe benefits for metabolic control (106-108), insulin requirement (106), inflammation, or arterial stiffness (108). Large variations in the amount of fiber across studies and the challenges in isolating this factor from other dietary components have confounded interpretation of the findings.

The GI was introduced by Jenkins et al. in 1981 (38), and GL was subsequently introduced to reflect the glycemic response to a food, meal, or diet as commonly consumed (109). Low-GI/GL diets have shown modest benefits for HbA1c levels in diabetes, typically in the range of about $0.5 \%$ (110-112). In T1D, improvements in glycemic control, reduced rates of hypoglycemia, and decreased insulin requirements have been observed (102, 113115). Additional benefits include improved quality of life (115), reduced lipid levels (114), and weight loss (116). Other studies failed to show any benefits from a low-GI diet (117). Study limitations include small sample sizes, variable study duration (range 12 days to 12 weeks for randomized controlled trials), dietary heterogeneity, and low intervention intensity, as discussed below.

\section{Carbohydrate amount}

With the possible exception of nursing infants, humans at all stages of life can survive with virtually no dietary carbohydrate, as evidenced by hunter-gatherer populations living at high latitudes that had little access to plant foods (the only significant source of carbohydrate, other than breast milk) throughout most of the year. Therefore, for the purposes of this Review, the question arises of what level of carbohydrate intake is optimal for glycemic control and prevention of complications in people with diabetes.

Diets focused on carbohydrate amount can be characterized with reference to prevailing intakes as high-carbohydrate ( $\geq 45 \%$ EI, "standard") and reduced-carbohydrate $(<45 \% \mathrm{EI})$. Reduced-carbohydrate diets can be further categorized as moderate-carbohydrate (MC; 26\%-44\% EI), low-carbohydrate (LC; $10 \%-25 \% \mathrm{EI}$ ), very-low-carbohydrate (VLC; <10\% EI), and ketogenic, according to the relative or absolute amount of digestible carbohydrate consumed, as summarized in Table $1(5,118)$. While these definitions are somewhat arbitrary, the term ketogenic refers to a physiologically distinctive state. With restriction of digestible carbohydrate intake to a critical threshold (typically $\leq 30-50 \mathrm{~g} / \mathrm{d}$ ) and concurrent limitation of protein, the resulting high serum glucagon/insulin ratio increases rates of lipolysis and hepatic ketogenesis (119), producing concentrations of $\beta$-hydroxybutyrate (BOHB) typically between 0.5 and 5.0 $\mathrm{mmol} / \mathrm{L}$. This state of "nutritional ketosis" $(120,121)$ contrasts 
Table 1. Classification of reduced-carbohydrate diets

\begin{tabular}{|c|c|c|}
\hline Carbohydrate amount & Diet name & Defining features/Comments \\
\hline$\geq 45 \% \mathrm{El} ; \geq 225 \mathrm{~g} / \mathrm{d}$ & High-carbohydrate & $\begin{array}{l}\text { Prevailing dietary pattern in the US; consistent with recent } \\
\text { recommendations for people with diabetes and USDA recommendations } \\
\text { for general public }\end{array}$ \\
\hline $26 \%-44 \%$ El; $131-224 \mathrm{~g} / \mathrm{d}$ & Moderate-carbohydrate & $\begin{array}{l}\text { Moderate reduction of grains, starchy vegetables, added sugar } \\
\text { Unlimited legumes, whole fruits } \\
\text { Unlimited non-starchy vegetables }\end{array}$ \\
\hline $10 \%-25 \% \mathrm{El} ; 51-130 \mathrm{~g} / \mathrm{d}$ & Low-carbohydrate & $\begin{array}{l}\text { Substantial reduction of grains, starchy vegetables, added sugar } \\
\text { Moderate reduction of legumes, whole fruits } \\
\text { Unlimited non-starchy vegetables }\end{array}$ \\
\hline \multirow[t]{2}{*}{$<10 \% \mathrm{El} ; \leq 50 \mathrm{~g} / \mathrm{d}$} & Very-low-carbohydrate & $\begin{array}{l}\text { Elimination of grains, starchy vegetables, added sugar } \\
\text { Substantial reduction of legumes, whole fruits } \\
\text { Unlimited non-starchy vegetables }\end{array}$ \\
\hline & $\begin{array}{l}\text { Very-low-carbohydrate } \\
\text { ketogenic }\end{array}$ & $\begin{array}{l}\text { As above, with protein intake typically limited to } \leq 20 \% \text { of El } \\
\text { Serum BOHB characteristically } 0.5-5.0 \mathrm{mmol} / \mathrm{L}\end{array}$ \\
\hline
\end{tabular}

Calculations based on a 2000-kcal/d diet. BOHB, $\beta$-hydroxybutyrate; El, energy intake; USDA, US Department of Agriculture.
As noted in a recent meta-analysis (133), inferences regarding the efficacy of a reduced-carbohydrate diet in T1D are limited by small study size, short duration, dietary assessment methodology (e.g., self-report), and selection bias. Nevertheless, mirroring trends in the general population, popular interest in carbohydrate reduction for diabetes management has surged recently (134, 135), with several books focused on or including sections on VLC diets for T1D management (136-140).

Carbohydrate reduction in $T 2 D$. In the absence of well-controlled and -powered interventions in T1D, clinical trials of reducedcarbohydrate diets in $\mathrm{T} 2 \mathrm{D}$ may be informative, as both types with the uncontrolled ketone production characteristic of diabetic ketoacidosis most commonly due to insulin deficiency, in which BOHB typically exceeds $5 \mathrm{mmol} / \mathrm{L}$, and clinical derangements (e.g., dehydration, weight loss, nausea, altered mental state) may occur (Supplemental Table 1; supplemental material available online with this article; https://doi.org/10.1172/JCI142246DS1). In nutritional ketosis, ketone bodies constitute a primary fuel for the brain, decreasing dependency on glucose, with other potential metabolic benefits (e.g., related to chronic inflammation, oxidative stress, myocardial energy metabolism) (35, 122-124).

Carbohydrate reduction in T1D. The impact of macronutrients on glycemic control in T1D has been extensively studied among populations consuming high-carbohydrate diets. Therefore, we explored this relationship in a systematic search of studies focused on reduced-carbohydrate diets ( $<45 \% \mathrm{EI}, \geq 2$ months), as detailed in Table 2. We identified 24 articles in heterogeneous settings, including 4 randomized controlled trials (RCTs), 5 uncontrolled interventional studies, 3 observational studies, and 12 case reports or series.

While glycemic control on MC diets was similar to that of the general population with T1D, all LC and VLC studies reported mean HbA1c of less than 7.5\%. Moreover, in studies of VLC, $\mathrm{HbA1c}$ was in the normal range and insulin doses were low, with the exception of one case report. CGM showed remarkably stable glycemic profiles. For instance, among 316 respondents in an online community of children and adults with documented T1D following a VLC diet for at least 3 months, mean HbA1c was $5.67 \%$, daily insulin dose was $0.4 \mathrm{U} / \mathrm{kg} / \mathrm{d}$, mean CGM glucose was $104 \mathrm{mg} / \mathrm{dL}$, and mean CGM glucose standard deviation was 36 $\mathrm{mg} / \mathrm{dL}$ (125). Likewise, short-term RCTs comparing LC $(126,127)$ or VLC (128) with HC diets showed reductions in HbA1c (126), insulin doses (126-128), glycemic variability, and time spent in hypoglycemia $(127,128)$. When reported, severe hypoglycemia and diabetic ketoacidosis were infrequent or reduced compared with the prediet period $(125,129-132)$. Lipid levels varied, with generally favorable triglyceride/HDL-cholesterol ratio but elevated LDL-cholesterol in several case reports. of diabetes share key pathophysiological features (i.e., glucose intolerance and peripheral hyperinsulinemia) and comorbidities. Meta-analyses of trials comparing reduced-carbohydrate versus higher-carbohydrate diets or standard of care report modestly lower HbA1c ( 0.5\%) (141-147) and reduced usage of glucoselowering medications $(142,144,145,147)$, suggesting a clinical benefit greater than that reflected by $\mathrm{HbA1c}$ alone. As in studies in T1D, the reduced-carbohydrate diets produced favorable changes in triglycerides and HDL-cholesterol (141-146); effects on LDL-cholesterol were inconsistent, with no marked increase seen in any meta-analysis. Effects were also reported in studies without substantial weight loss (143-147), suggesting the potential of a weight-independent benefit of carbohydrate reduction. However, dietary adherence and glycemic effects diminish over time (148), and the efficacy of carbohydrate restriction for hard clinical outcomes - micro- and macrovascular disease, organ failure, or premature death - has not been established.

The generally moderate magnitude of benefits observed in these and other diet studies should be interpreted in light of fundamental design limitations common to most of these trials. Recognizing the difficulty of maintaining major dietary change over the long term for most people $(149,150)$, trials focused on the potential efficacy of novel diets - and especially a reduced-carbohydrate diet in the modern food environment - should use high-intensity interventions to facilitate behavioral change and differentiation between dietary groups, potentially incorporating food provision, individual counseling from a behavior modification specialist, cooking classes, daily internet support, and more. However, most published trials have depended on low-intensity interventions, typically consisting of nutritional education and group dietary counseling. Indeed, as shown by van Wyk et al. (148), dietary adherence is often low, with little difference in carbohydrate intake between treatment groups in many long-term behavioral trials.

The findings of one recent, nonrandomized trial suggest that carbohydrate restriction may be sustainable and efficacious when combined with high-intensity individual support (151). Among 
Table 2. Reports on reduced-carbohydrate diets in people with T1D

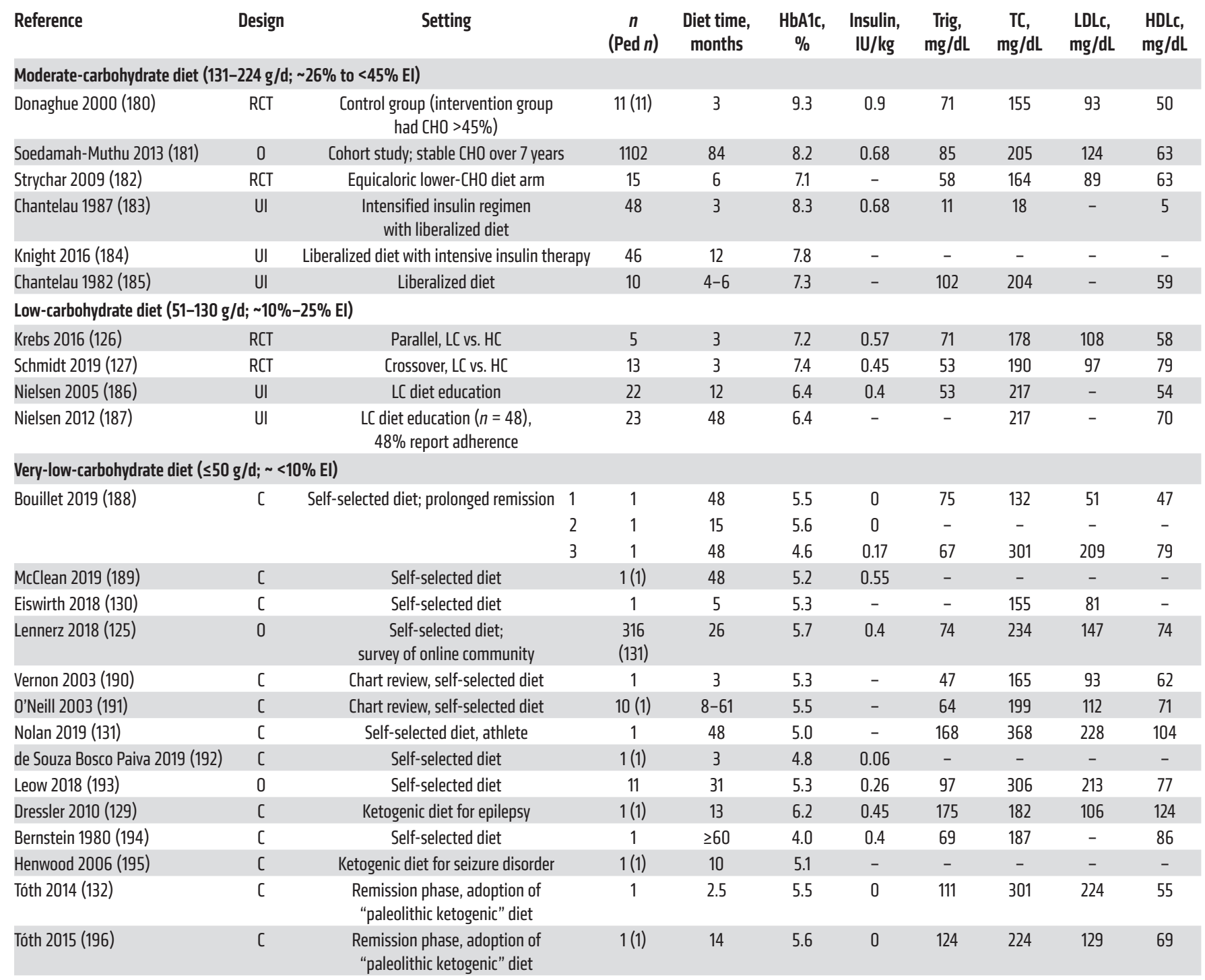

To examine the relationship between dietary carbohydrate amount and glycemic control among reduced-carbohydrate diets, we conducted a PubMed search on May 1, 2020, with the query "(diabetes[title/abstract] OR diabetic[title/abstract]) AND (ketogenic[Title/abstract] OR carbohydrate[Title/ abstract]) AND insulin NOT type 2 NOT animal," limited to English language and human articles. A total of 1358 publications were identified, independently reviewed, and cross-referenced by authors, from which 24 studies were selected based on these criteria: (a) included a group with T1D; (b) carbohydrate $<45 \% \mathrm{El}$; and (c) reported HbA1c $\geq 2$ months on the diet. One case series confounded by insulin omission and other issues was excluded (169). For studies with multiple groups, only those meeting inclusion criteria were included. C, case report or series; CHO, carbohydrate. HC, high-carbohydrate; HDLc, HDLcholesterol; LC, low-carbohydrate; LDLc, LDL-cholesterol; $n$, number of eligible participants; O, observational; Ped $n$, number of pediatric participants; RCT, randomized controlled trial; TC, total cholesterol; Trig, triglycerides; UI, uncontrolled intervention; “-”, not reported.

262 adults with T2D prescribed a ketogenic diet and provided with a novel "continuous care intervention" (e.g., Web-based resources, tracking tools, telemedicine support), 74\% completed the 2-year follow-up period. Among them, mean weight loss was $11.9 \mathrm{~kg}$, mean HbA1c decreased by $0.9 \%$, and use of glucose-lowering medications (other than metformin) decreased by more than 50\%. "Diabetes reversal," defined as HbA1c $<6.5 \%$, without glucose-lowering medications other than metformin, occurred in $53.5 \%$ of participants. A usual-care comparison group showed no improvements in outcomes. A second recent trial compared a less restrictive LC diet (with $90 \mathrm{~g} / \mathrm{d}$ carbohydrate) versus a conventional low-fat $(\leq 30 \% \mathrm{EI})$ diet in 85 patients with poorly controlled T2D (152). After 18 months, the LC group maintained good dietary adherence and had lower HbA1c, weight, waist circumference, and blood pressure. Carotid intima-media thickness was nonsignificantly $(P=0.08)$ improved in the LC group. High-quality RCTs will be needed to assess the generalizability of these findings.

Meta-analyses do not suggest special safety concerns for carbohydrate-restricted diets in T2D (141-147), although long-term and well-powered trials will also be needed to address this ques- 
tion. For individuals taking insulin or drugs that increase insulin action, medical supervision is needed to guide dose adjustment to prevent hypoglycemia. Since carbohydrate-restricted diets are not inherently high in protein, impairment of renal function would not necessarily preclude their use.

\section{Safety concerns about very-low-carbohydrate diets for T1D}

Despite more than a century of clinical experience with low-carbohydrate diets, considerable controversy persists regarding the safety of VLC diets for the public in general and people with diabetes in particular (134). Specific concerns in T1D relate to risk for hypoglycemia and ketoacidosis; general concerns include cardiovascular risk, nutrient deficiencies, and poor growth in children.

Hypoglycemia. While hypoglycemia may occur without appropriate insulin dose reduction, a VLC diet may lower the risk for this complication through reduction in prandial insulin requirements, thus ameliorating the difficulty of controlling early postprandial hyperglycemia without causing late postprandial hypoglycemia. In support of this possibility, two RCTs found less time spent in hypoglycemia below $54 \mathrm{mg} / \mathrm{dL}$ on carbohydrate-reduced versus high-carbohydrate diets $(127,128)$. Severe hypoglycemic events were not noted in any of the reviewed case reports, and the online survey cited above (125) reported few such events among respondents after adoption of a VLC diet relative to their prediet period and compared with rates in the general T1D population $(153,154)$. Another potential advantage of a VLC diet is the neuroprotection conferred by nutritional ketosis for not only symptomatic hypoglycemia, but also long-term brain health (122, 155-158). Landmark experiments by Cahill (159) and others (156) show that, with adaptation to ketosis following a prolonged fast, research participants without diabetes injected with insulin to produce severe hypoglycemia (mean BG $<40 \mathrm{mg} / \mathrm{dL}$, and, in one case, $9 \mathrm{mg} / \mathrm{dL}$ ) experienced no symptoms and showed no evidence of a counter-regulatory hormonal response. However, no high-quality longer-term prospective data are available to assess this risk in the context of nutritional ketosis and diabetes management.

Ketoacidosis. Concern has been expressed that severe ketoacidosis might develop more easily from the baseline nutritional ketosis associated with a VLC diet or that the transition from physiological to pathological ketosis might be hard to recognize. However, the amount of insulin (endogenously secreted or exogenously administered) necessary to maintain normal BG is almost always sufficient to prevent a pathological rise in ketoacids by suppressing excessive lipolysis and ketogenesis. In fact, people on a VLC diet, by virtue of having more normal and less variable glycemic patterns, can use relatively small increases in BG (e.g., to $180 \mathrm{mg} / \mathrm{dL}$ ) as an early indication of physiological stress and possible under-insulinization and an early warning sign of impending pathological increase in ketoacid concentrations. Ketoacidosis was not noted in any of the reviewed case reports, and the online survey found low rates of hospitalization for ketoacidosis in individuals after adoption of a VLC diet relative to their prediet period (125) and to rates in the general T1D population $(153,154)$.

The possibility of euglycemic ketoacidosis remains a theoretical concern, with rare case reports among patients with T1D (160) when vomiting occurs or patients are unable to tolerate food intake, and in the general public $(161,162)$ following a VLC diet.
Although it has not been described in people with T1D in conjunction with a VLC diet, the occurrence of this complication with use of sodium-glucose cotransporter-2 (SGLT2) inhibitors - a class of drugs that, analogous to a VLC diet, decreases insulin requirements and shifts metabolism from carbohydrate to fat $(163,164)$ - emphasizes the need for vigilance.

Cardiovascular disease risk. Carbohydrate-reduced diets may increase total and LDL-cholesterol in the general population, mediated in part by higher intake of saturated fats. These elevations have been inconsistently observed in people with T1D or T2D. For individuals who do experience an increase, improvements in triglycerides and HDL-cholesterol may attenuate or counterbalance the adverse effects of high LDL-cholesterol, although this possibility remains speculative. Moreover, a VLC diet may selectively enrich large, buoyant LDL particle subspecies that have a weaker association with CVD than smaller dense LDL particles (165). In analyses of adolescents and young adults who participated in the DCCT and Epidemiology of Diabetes Interventions and Complications (EDIC) study - a longitudinal, observational study using the DCCT cohort to determine the long-term effects of glycemic levels on micro- and macrovascular outcomes - HbA1c was the strongest modifiable predictor of cardiovascular events, followed by triglycerides; LDL-cholesterol had weaker associations (166). This observation is consistent with the 2014 ADA and American Heart Association consensus statement that reported a weaker association of CVD events with LDL-cholesterol elevation than with poor glycemic control or other risk factors (167). Furthermore, high LDL-cholesterol can be more effectively treated with drugs, and with fewer adverse effects, than metabolic syndrome components for which carbohydrate restriction may be especially effective.

Nutritional insufficiency. Like other restrictive diets, VLC diets have been linked to various nutrient deficiencies $(134,168,169)$. These observations highlight the importance of ensuring proper formulation and professional oversight in prescribing carbohydrate reduction for diabetes. Even with a daily limit of $50 \mathrm{~g}$ carbohydrate, a VLC diet can include regular consumption of dairy products, nuts, seeds, non-starchy vegetables, and limited amounts of low-sugar fruits (e.g., berries). On diets with less severe carbohydrate restriction, moderate amounts of legumes and grains can also be incorporated.

Growth. Poor growth has been reported among children with epilepsy treated with a ketogenic diet. However, the macronutrient composition used for refractory epilepsy may be more extreme (sometimes with fat $>80 \%$ EI) than would be used in other clinical settings, and these children may have other complicating medical issues or drug treatments that affect growth $(124,170,171)$. Growth delay has also been reported in children with T1D following a VLC diet (169); however, with possible concurrent insulin omission and other confounding factors, a causal relationship cannot be readily established from the limited available data. In the online survey (125), a modest decrease in height percentile since diagnosis was reported in 34 children, but the magnitude of the growth deceleration was similar to that observed in large diabetes registries and potentially related to metabolic stress surrounding diagnosis and implementation of treatment (172-174). Prospective studies are needed to address this concern. 
Other concerns. Restrictive dieting, which is associated with eating disorders in the general population, may be of special concern for people with T1D, who are at increased risk for disordered eating (175). Adherence is also a concern. While VLC diets are popular and people who chose them report high satisfaction with their diet (125), studies on carbohydrate restriction report high rates of attrition (148). This may relate to the inherent challenges of behavior change and, as noted above, the low intervention intensity characteristic of most diet trials. In fact, restrictive diets have a long history of success for numerous specific conditions - such as celiac disease, phenylketonuria, and severe food allergies - when they provide symptom relief or other tangible benefits. With widespread usage of CGM, patients with diabetes may observe a marked reduction in postprandial hyperglycemia on a carbohydrate-restricted diet, providing not only immediate positive feedback, but also the hope of preventing much-feared diabetes complications. Furthermore, benefits might be achievable with flexible approaches, such as combining moderate carbohydrate reduction (e.g., 25\% EI) with a focus on reducing GI, allowing for daily consumption of nontropical fruits, legumes, and modest portions of whole-kernel grains.

\section{Economic considerations}

The total annual economic costs of diabetes in the United States were estimated at $\$ 327$ billion in 2017, including approximately $\$ 15$ billion for insulin. Of major concern, the cost of insulin analogs has increased enormously, with some patients now paying in excess of $\$ 800$ per month $(176,177)$. By reducing both the need for expensive, rapid-acting insulin analogs (to better match glucose absorption rates on a high-carbohydrate diet) and the total daily insulin dose required, a VLC diet might substantially lower outof-pocket costs to patients with both types of diabetes. If carbohydrate restriction were to help prevent or treat $\mathrm{T} 2 \mathrm{D}$, the incidence of which has greatly increased in recent decades (178), the medical cost savings could be much greater.

\section{Conclusion}

Reduced-carbohydrate diets have been used to treat diabetes for more than a century. After the discovery of insulin, high-carbohy- drate diets became the mainstay of MNT for diabetes, not because of demonstrated superiority for long-term outcomes, but because insulin could ameliorate the acute metabolic effects of carbohydrate consumption. Additional impetus for use of a high-carbohydrate diet in diabetes arose from concern for ketoacidosis in an era when the distinction between nutritional ketosis and ketoacidosis was not well understood. Moreover, the lack of practical methods for frequent BG monitoring delayed recognition of the ubiquity of postprandial hyperglycemia. Subsequently, a high-carbohydrate, low-fat diet was promoted to reduce serum cholesterol, even as evidence for an adverse effect on the development of metabolic syndrome accrued. Despite major pharmacological and technological developments, outcomes of management of T1D remain suboptimal, and the prevalence of T2D has greatly increased, placing many people at risk for micro- and macrovascular complications.

With new understanding of the importance of controlling postprandial hyperglycemia, mitigating glycemic variability, and ameliorating metabolic syndrome, carbohydrate restriction has gained renewed attention. Preliminary research suggests that this dietary approach might transform clinical management and perhaps normalize HbA1c for many people with diabetes, at substantially reduced treatment costs. High-quality RCTs, with intensive support for behavior changes, will be needed to address this possibility and assess long-term safety and sustainability (Supplemental Table 2). With total medical costs of diabetes in the United States approaching $\$ 1$ billion a day (179), this research must assume high priority.

\section{Acknowledgments}

We thank Owen Henn for assistance with literature review, data extraction, and analysis of macronutrient composition. We also thank Gary Taubes and Eric Westman for critical review of the manuscript. BSL was supported by grant 5 K23 DK119546-02, and SA by grant 5 T32 DK007699-39, both from the National Institute of Diabetes and Digestive and Kidney Diseases.

Address correspondence to: Belinda S. Lennerz or David S. Ludwig, Boston Children's Hospital, 300 Longwood Avenue, Boston, Massachusetts 02115, USA. Email: belinda.lennerz@childrens.harvard. edu (BSL). Email: david.ludwig@childrens.harvard.edu (DSL).
1. Evert AB, et al. Nutrition therapy for adults with diabetes or prediabetes: a consensus report. Diabetes Care. 2019;42(5):731-754.

2. Owens DR, Bolli GB. The continuing quest for better subcutaneously administered prandial insulins: a review of recent developments and potential clinical implications. Diabetes Obes Metab. 2020;22(5):743-754.

3. Ceriello A, et al. Postprandial glucose regulation and diabetic complications. Arch Intern Med. 2004;164(19):2090-2095.

4. Slattery D, Amiel SA, Choudhary P. Optimal prandial timing of bolus insulin in diabetes management: a review. Diabet Med. 2018;35(3):306-316.

5. Feinman RD, et al. Dietary carbohydrate restriction as the first approach in diabetes management: critical review and evidence base. Nutrition. 2015;31(1):1-13.

6. Rollo J. Account of two cases of diabetes mellitus, with remarks. Ann Med (Edinb). 1797;2:85-105.

7. Woodyatt RT. Objects and method of diet adjustment in diabetes. Arch Intern Med. 1921;28(2):125-141.

8. Naunyn B. Der Diabetes Mellitus. Alfred Hoelder; 1906.

9. Ebstein W. Über die Lebensweise der Zuckerkranken. J.F. Bergmann; 1898.

10. Allen F. Prolonged fasting in diabetes. Am JMed Sci. 1915;150:480-485.

11. Joslin EP. Present-day treatment and prognosis in diabetes. Am J Med Sci. 1915;150:485-495.

12. Joslin EP. The treatment of diabetes mellitus. Can Med Assoc J. 1916;6(8):673-684.

13. Mazur A. Why were "starvation diets" promoted for diabetes in the pre-insulin period? Nutr J. 2011;10:23.

14. Newburgh LH, Marsh PL. Use of a high fat diet in the treatment of diabetes mellitus: first paper.
Arch Intern Med. 1921;27(6):699-705.

15. Henderson G. Court of last appeal - the early history of the high-fat diet for diabetes. J Diabetes Metab. 2016;7:8.

16. Wilder RM. 'Optimal' diets for diabetic patients. JAMA. 1924;83(10):733-737.

17. Geyelin HR. The treatment of diabetes with insulin (after 10 years). JAMA. 1935;104(14):1203-1208.

18. Rabinowitch IM. Effects of the high carbohydrate-low calorie diet upon carbohydrate tolerance in diabetes mellitus. Can Med Assoc J. 1935;33(2):136-144.

19. Rabinowitch IM. Experiences with a high carbohydrate-low calorie diet for the treatment of diabetes mellitus. Can Med Assoc J. 1930;23(4):489-498.

20. Himsworth HP. High carbohydrate diets and insulin efficiency. Br Med J. 1934;2(3836):57-60.

21. Falta W. The therapy of diabetes mellitus. Arch 
Intern Med (Chic). 1909;III(2):159-174.

22. Tolstoi E, Almy TP, Toscani V. Treatment of diabetes mellitus with protamine insulin: is a persistent glycosuria harmful? A metabolic study of a severe case. Ann Intern Med. 1942;16(5):893-903.

23. Stamler J. Established major coronary risk factors: historical overview. In: Marmot M, Elliott P, eds. Coronary Heart Disease Epidemiology: From Aetiology to Public Health. Oxford University Press; 2005:1-21.

24. Diabetes Control Complications Trial Research Group, et al. The effect of intensive treatment of diabetes on the development and progression of long-term complications in insulindependent diabetes mellitus. NEngl JMed. 1993;329(14): $977-986$.

25. Joslin E. Fat and the diabetic. N Engl JMed. 1933;209:519-528.

26. Singh I. Low-fat diet and therapeutic doses of insulin in diabetes mellitus. Lancet. 1955;268(6861):422-425.

27. Rabinowitch IM. Arteriosclerosis in diabetes. Ann Intern Med. 1935;8(11):1436-1474.

28. Strouse S, Soskin S. Treatment of the same diabetic patient with widely varying diets. Trans Assoc Am Physicians. 1932;47:317-322.

29. Bierman EL, Hamlin JT. The hyperlipemic effect of a low-fat, high-carbohydrate diet in diabetic subjects. Diabetes. 1961;10:432-437.

30. Albrink MJ. Diet, diabetes, and serum lipids. Diabetes. 1964;13:425-429.

31. Richter CP,Edward C, Smith H Jr. Increased fat and decreased carbohydrate appetite of pancreatectomized rats. Endocrinology. 1941;28(2):179-192.

32. Richter CP, Schmidt ECH, Malone PD. Further observations on the self-regulatory dietary selections of rats made diabetic by pancreatectomy. Bull Johns Hopkins Hosp. 1945;76:192-219.

33. [No authors listed]. Principles of nutrition and dietary recommendations for patients with diabetes mellitus: 1971. Diabetes. 1971;20(9):633-634.

34. Nuttall FQ, Brunzell DJ. Principles of nutrition and dietary recommendations for individuals with diabetes mellitus: 1979. American Diabetes Association. Diabetes. 1979;28(11):1027-1030.

35. Ludwig DS, Willett WC, Volek JS, Neuhouser ML. Dietary fat: from foe to friend? Science. 2018;362(6416):764-770.

36. Anderson JW, Ward K. High-carbohydrate, highfiber diets for insulin-treated men with diabetes mellitus. Am JClin Nutr. 1979;32(11):2312-2321.

37. Story L, Anderson JW, Chen WJ, Karounos D, Jefferson B. Adherence to high-carbohydrate, highfiber diets: long-term studies of non-obese diabetic men. J Am Diet Assoc. 1985;85(9):1105-1110.

38. Jenkins DJ, et al. Glycemic index of foods: a physiological basis for carbohydrate exchange. Am J Clin Nutr. 1981;34(3):362-366.

39. [No authors listed]. Nutritional recommendations and principles for individuals with diabetes mellitus: 1986. American Diabetes Association. Diabetes Care. 1987;10(1):126-132.

40. Delahanty LM, et al. Association of diet with glycated hemoglobin during intensive treatment of type 1 diabetes in the Diabetes Control and Complications Trial. Am J Clin Nutr. 2009;89(2):518-524.
41. Anderson EJ, et al. Nutrition interventions for intensive therapy in the Diabetes Control and Complications Trial. The DCCT Research Group. JAm Diet Assoc. 1993;93(7):768-772.

42. American Diabetes Association. Nutrition recommendations and principles for people with diabetes mellitus. Diabetes Care. 2000;23(suppl 1):S43-S46.

43. American Diabetes Association Task Force for Writing Nutrition Principles Recommendations for the Management of Diabetes Related Complications. American Diabetes Association position statement: evidence-based nutrition principles and recommendations for the treatment and prevention of diabetes and related complications. JAm Diet Assoc. 2002;102(1):109-118.

44. Bantle JP, et al. Nutrition recommendations and interventions for diabetes-2006: a position statement of the American Diabetes Association. Diabetes Care. 2006;29(9):2140-2157.

45. Evert AB, et al. Nutrition therapy recommendations for the management of adults with diabetes. Diabetes Care. 2014;37(suppl 1):S120-S143.

46. American Diabetes Association. 5. Lifestyle management: Standards of Medical Care in Diabetes-2019. Diabetes Care. 2019;42(suppl 1):S46-S60.

47. Smart CE, Annan F, Higgins LA, Jelleryd E, Lopez M, Acerini CL. ISPAD Clinical Practice Consensus Guidelines 2018: nutritional management in children and adolescents with diabetes. Pediatr Diabetes. 2018;19(suppl 27):136-154 .

48. Tattersall RB. The quest for normoglycaemia: a historical perspective. Diabet Med. 1994;11(7):618-635.

49. Berger M, Mühlhauser I. Implementation of intensified insulin therapy: a European perspective. Diabet Med.1995;12(3):201-208.

50. Wylie-Rosett J. The role of carbohydrate counting in type 1 diabetes. Lancet Diabetes Endocrinol. 2014;2(2):97-98.

51. Wolfsdorf J, Mehta S, Quinn M, Warham K. In: Duggan CW, Koletzko B, Walker A, eds. Nutrition in Pediatrics: Basic Science-Clinical Applications. People's Medical Publishing House-USA; 2016:891-910.

52. Bishop F, et al. The carbohydrate counting in adolescents with type 1 diabetes (CCAT) study. Diabetes Spectrum. 2009;22(1):56-62.

53. Smart CE, Ross K, Edge JA, King BR, McElduff P, Collins CE. Can children with Type 1 diabetes and their caregivers estimate the carbohydrate content of meals and snacks? Diabet Med. 2010;27(3):348-353.

54. Ahola AJ, et al. Many patients with Type 1 diabetes estimate their prandial insulin need inappropriately. J Diabetes. 2010;2(3):194-202.

55. Smart CE, et al. Both dietary protein and fat increase postprandial glucose excursions in children with type 1 diabetes, and the effect is additive. Diabetes Care. 2013;36(12):3897-3902.

56. Bell KJ, Smart CE, Steil GM, Brand-Miller JC, King $\mathrm{B}$, Wolpert HA. Impact of fat, protein, and glycemic index on postprandial glucose control in type 1 diabetes: implications for intensive diabetes management in the continuous glucose monitoring era. Diabetes Care. 2015;38(6):1008-1015

57. Paterson MA, King BR, Smart CEM, Smith T, Rafferty J, Lopez PE. Impact of dietary protein on postprandial glycaemic control and insulin requirements in Type 1 diabetes: a systematic review. Diabet Med. 2019;36(12):1585-1599.

58. Paterson MA, et al. Increasing the protein quantity in a meal results in dose-dependent effects on postprandial glucose levels in individuals with Type 1 diabetes mellitus. Diabet Med. 2017;34(6):851-854.

59. Felig P, Wahren J, Sherwin R, Palaiologos G. Amino acid and protein metabolism in diabetes mellitus. Arch Intern Med. 1977;137(4):507-513.

60. Winiger G, Keller U, Laager R, Girard J, Berger W. Protein content of the evening meal and nocturnal plasma glucose regulation in type-I diabetic subjects. Horm Res. 1995;44(3):101-104.

61. Brown RJ, Sinaii N, Rother KI. Too much glucagon, too little insulin: time course of pancreatic islet dysfunction in new-onset type 1 diabetes. Diabetes Care. 2008;31(7):1403-1404.

62. Wolpert HA, Atakov-Castillo A, Smith SA, Steil GM. Dietary fat acutely increases glucose concentrations and insulin requirements in patients with type 1 diabetes: implications for carbohydrate-based bolus dose calculation and intensive diabetes management. Diabetes Care. 2013;36(4):810-816.

63. Bell KJ, et al. Amount and type of dietary fat, postprandial glycemia, and insulin requirements in type 1 diabetes: a randomized within-subject trial. Diabetes Care. 2020;43(1):59-66.

64. Homko C, Deluzio A, Jimenez C, Kolaczynski JW, Boden G. Comparison of insulin aspart and lispro: pharmacokinetic and metabolic effects. Diabetes Care. 2003;26(7):2027-2031.

65. Pennant ME, Bluck LJ, Marcovecchio ML, Salgin B, Hovorka R, Dunger DB. Insulin administration and rate of glucose appearance in people with type 1 diabetes. Diabetes Care. 2008;31(11):2183-2187.

66. Luijf YM, van Bon AC, Hoekstra JB, Devries JH. Premeal injection of rapid-acting insulin reduces postprandial glycemic excursions in type 1 diabetes. Diabetes Care. 2010;33(10):2152-2155.

67. Cryer PE, Davis SN, Shamoon H. Hypoglycemia in diabetes. Diabetes Care. 2003;26(6):1902-1912.

68. Marks BE, Wolfsdorf JI. Monitoring of pediatric type 1 diabetes. Front Endocrinol (Lausanne). 2020;11:128.

69. DAFNE Study Group. Training in flexible, intensive insulin management to enable dietary freedom in people with type 1 diabetes: dose adjustment for normal eating (DAFNE) randomised controlled trial. BMJ. 2002;325(7367):746.

70. Mehta SN, et al. Dietary behaviors predict glycemic control in youth with type 1 diabetes. Diabetes Care. 2008;31(7):1318-1320.

71. Foster NC, et al. State of type 1 diabetes management and outcomes from the T1D exchange in 2016-2018. Diabetes Technol Ther. 2019;21(2):66-72.

72. Brown SA, et al. Six-month randomized, multicenter trial of closed-loop control in type 1 diabetes. N Engl J Med. 2019;381(18):1707-1717.

73. Bruemmer D, Nissen SE. Prevention and management of cardiovascular disease in patients with diabetes: current challenges and opportunities. Cardiovasc Endocrinol Metab. 2020;9(3):81-89.

74. Kazemian P, Shebl FM, McCann N, Walensky RP, Wexler DJ. Evaluation of the cascade of diabetes 
care in the United States, 2005-2016. JAMA Intern Med. 2019;179(10):1376-1385.

75. Rawshani A, Rawshani A, Gudbjörnsdottir S. Mortality and cardiovascular disease in type 1 and type 2 diabetes. NEngl JMed. 2017;377(3):300-301.

76. Rawshani A, et al. Excess mortality and cardiovascular disease in young adults with type 1 diabetes in relation to age at onset: a nationwide, register-based cohort study. Lancet. 2018;392(10146):477-486.

77. Slama G, et al. Correlation between the nature and amount of carbohydrate in meal intake and insulin delivery by the artificial pancreas in 24 insulin-dependent diabetics. Diabetes. 1981;30(2):101-105.

78. Halfon P, Belkhadir J, Slama G. Correlation between amount of carbohydrate in mixed meals and insulin delivery by artificial pancreas in seven IDDM subjects. Diabetes Care. 1989;12(6):427-429.

79. Rabasa-Lhoret R, Garon J, Langelier H, Poisson $D$, Chiasson JL. Effects of meal carbohydrate content on insulin requirements in type 1 diabetic patients treated intensively with the basal-bolus (ultralente-regular) insulin regimen. Diabetes Care. 1999;22(5):667-673.

80. Wolever TM, et al. Prediction of the relative blood glucose response of mixed meals using the white bread glycemic index. Diabetes Care. 1985;8(5):418-428.

81. Jenkins DJ, et al. Metabolic effects of a low-glycemic-index diet. Am JClin Nutr. 1987;46(6):968-975.

82. Miller JC. Importance of glycemic index in diabetes. Am JClin Nutr. 1994;59 (3 suppl):747S-752S.

83. Finley CE, Barlow CE, Halton TL, Haskell WL. Glycemic index, glycemic load, and prevalence of the metabolic syndrome in the cooper center longitudinal study. J Am Diet Assoc. 2010;110(12):1820-1829.

84. Schwingshackl L, Hobl LP, Hoffmann G. Effects of low glycaemic index/low glycaemic load vs. high glycaemic index/ high glycaemic load diets on overweight/obesity and associated risk factors in children and adolescents: a systematic review and meta-analysis. Nutr J. 2015;14:87.

85. Zhang JY, Jiang YT, Liu YS, Chang Q, Zhao YH, $\mathrm{Wu} \mathrm{QJ}$. The association between glycemic index, glycemic load, and metabolic syndrome: a systematic review and dose-response metaanalysis of observational studies. Eur J Nutr. 2020;59(2):451-463.

86. Wang HH, Lee DK, Liu M, Portincasa P, Wang DQ. Novel insights into the pathogenesis and management of the metabolic syndrome. Pediatr Gastroenterol Hepatol Nutr. 2020;23(3):189-230.

87. Kapellen TM, et al. Children and adolescents with type 1 diabetes in Germany are more overweight than healthy controls: results comparing DPV database and CrescNet database. J Pediatr Endocrinol Metab. 2014;27(3-4):209-214.

88. Purnell JQ, Hokanson JE, Marcovina SM, Steffes MW, Cleary PA, Brunzell JD. Effect of excessive weight gain with intensive therapy of type 1 diabetes on lipid levels and blood pressure: results from the DCCT. Diabetes Control and Complications Trial. JAMA. 1998;280(2):140-146.
89. Priya G, Kalra S. A review of insulin resistance in type 1 diabetes: is there a place for adjunctive metformin? Diabetes Ther. 2018;9(1):349-361.

90. Polsky S, Ellis SL. Obesity, insulin resistance, and type 1 diabetes mellitus. Curr Opin Endocrinol Diabetes Obes. 2015;22(4):277-282.

91. [No authors listed]. Weight gain associated with intensive therapy in the diabetes control and complications trial. The DCCT Research Group. Diabetes Care. 1988;11(7):567-573.

92. [No authors listed]. Influence of intensive diabetes treatment on body weight and composition of adults with type 1 diabetes in the Diabetes Control and Complications Trial. Diabetes Care. 2001;24(10):1711-1721.

93. Fröhlich-Reiterer EE, et al. Predictors of increasing BMI during the course of diabetes in children and adolescents with type 1 diabetes: data from the German/Austrian DPV multicentre survey. Arch Dis Child. 2014;99(8):738-743.

94. Carlson MG, Campbell PJ. Intensive insulin therapy and weight gain in IDDM. Diabetes. 1993;42(12):1700-1707.

95. Imamura F, et al. Consumption of sugar sweetened beverages, artificially sweetened beverages, and fruit juice and incidence of type 2 diabetes: systematic review, meta-analysis, and estimation of population attributable fraction. BMJ. 2015;351:h3576.

96. Hu EA, Pan A, Malik V, Sun Q. White rice consumption and risk of type 2 diabetes: meta-analysis and systematic review. BMJ. 2012;344:e1454.

97. Bidel Z, Teymoori F, Davari SJ, Nazarzadeh M. Potato consumption and risk of type 2 diabetes: a dose-response meta-analysis of cohort studies. Clin Nutr ESPEN. 2018;27:86-91.

98. Livesey G, et al. Dietary glycemic index and load and the risk of type 2 diabetes: a systematic review and updated meta-analyses of prospective cohort studies. Nutrients. 2019;11(6):E1280.

99. Weickert MO, Pfeiffer AFH. Impact of dietary fiber consumption on insulin resistance and the prevention of type 2 diabetes. J Nutr. 2018;148(1):7-12.

100. Reynolds AN, Akerman AP, Mann J. Dietary fibre and whole grains in diabetes management: systematic review and meta-analyses. PLoS Med. 2020;17(3):e1003053.

101.Simpson HC, et al. A high carbohydrate leguminous fibre diet improves all aspects of diabetic control. Lancet. 1981;1(8210):1-5.

102. Giacco R, et al. Long-term dietary treatment with increased amounts of fiber-rich low-glycemic index natural foods improves blood glucose control and reduces the number of hypoglycemic events in type 1 diabetic patients. Diabetes Care. 2000;23(10):1461-1466.

103. Basu A, Alman AC, Snell-Bergeon JK. Dietary fiber intake and glycemic control: coronary artery calcification in type 1 diabetes (CACTI) study. Nutr J. 2019;18(1):23.

104. Bernaud FS, et al. Fiber intake and inflammation in type 1 diabetes. Diabetol Metab Syndr. 2014;6:66.

105. Schoenaker DA, Toeller M, Chaturvedi N, Fuller JH, Soedamah-Muthu SS, EURODIAB Prospective Complications Study Group. Dietary saturated fat and fibre and risk of cardiovascular disease and all-cause mortality among type 1 diabetic patients: the EURODIAB Prospective Complications Study. Diabetologia. 2012;55(8):2132-2141.

106.Venhaus A, Chantelau E. Self-selected unrefined and refined carbohydrate diets do not affect metabolic control in pump-treated diabetic patients. Diabetologia. 1988;31(3):153-157.

107. Lindsay AN, Hardy S, Jarrett L, Rallison ML. High-carbohydrate, high-fiber diet in children with type I diabetes mellitus. Diabetes Care. 1984;7(1):63-67.

108. Jaacks LM, et al. No association of dietary fiber intake with inflammation or arterial stiffness in youth with type 1 diabetes. J Diabetes Complications. 2014;28(3):305-310.

109. Brand-Miller JC, Thomas M, Swan V, Ahmad ZI, Petocz P, Colagiuri S. Physiological validation of the concept of glycemic load in lean young adults. J Nutr. 2003;133(9):2728-2732.

110. Thomas D, Elliott EJ. Low glycaemic index, or low glycaemic load, diets for diabetes mellitus. Cochrane Database Syst Rev. 2009;2009(1):CD006296.

111. Wang Q, Xia W, Zhao Z, Zhang H. Effects comparison between low glycemic index diets and high glycemic index diets on HbA1c and fructosamine for patients with diabetes: a systematic review and meta-analysis. Prim Care Diabetes. 2015;9(5):362-369.

112. Zafar MI, et al. Low-glycemic index diets as an intervention for diabetes: a systematic review and meta-analysis. Am J Clin Nutr. 2019;110(4):891-902.

113. Collier G, et al. Low glycaemic index starchy foods improve glucose control and lower serum cholesterol in diabetic children. Diabetes Nutr Metab. 1988;1(1):11-9.

114. Fontvieille AM, et al. A moderate switch from high to low glycaemic-index foods for 3 weeks improves the metabolic control of Type I (IDDM) diabetic subjects. Diabetes Nutr Metab. 1988;1:139-143.

115. Gilbertson HR, Brand-Miller JC, Thorburn AW, Evans S, Chondros P, Werther GA. The effect of flexible low glycemic index dietary advice versus measured carbohydrate exchange diets on glycemic control in children with type 1 diabetes. Diabetes Care. 2001;24(7):1137-1143.

116. Burani J, Longo PJ. Low-glycemic index carbohydrates: an effective behavioral change for glycemic control and weight management in patients with type 1 and 2 diabetes. Diabetes Educ. 2006;32(1):78-88.

117. Chiasson J-L. Glycemic index of foods and glycemic control in type I diabetes. Curr Opin Endocrinol Diabetes. 2000;7(1):25-30.

118. Shan Z, et al. Trends in dietary carbohydrate, protein, and fat intake and diet quality among US adults, 1999-2016. JAMA. 2019;322(12):1178-1187.

119. Poff AM, Koutnik AP, Egan B. Nutritional ketosis with ketogenic diets or exogenous ketones: features, convergence, and divergence. Curr Sports Med Rep. 2020;19(7):251-259.

120. Phinney SD, Bistrian BR, Wolfe RR, Blackburn GL. The human metabolic response to chronic ketosis without caloric restriction: physical and biochemical adaptation. Metabolism. 1983;32(8):757-768. 
121. Phinney SD. Ketogenic diets and physical performance. Nutr Metab (Lond). 2004;1(1):2.

122. Owen OE, Morgan AP, Kemp HG, Sullivan JM, Herrera MG, Cahill GF. Brain metabolism during fasting. JClin Invest. 1967;46(10):1589-1595.

123. Cahill GF, Aoki TT, Ruderman NB. Ketosis. Trans Am Clin Climatol Assoc. 1973;84:184-202.

124. Ludwig DS. The ketogenic diet: evidence for optimism but high-quality research needed. J Nutr. 2020;150(6):1354-1359.

125. Lennerz BS, et al. Management of type 1 diabetes with a very low-carbohydrate diet. Pediatrics. 2018;141(6):e20173349.

126. Krebs JD, Parry Strong A, Cresswell P, Reynolds AN, Hanna A, Haeusler S. A randomised trial of the feasibility of a low carbohydrate diet vs standard carbohydrate counting in adults with type 1 diabetes taking body weight into account. Asia Pac JClin Nutr. 2016;25(1):78-84.

127. Schmidt S, et al. Low versus high carbohydrate diet in type 1 diabetes: a 12-week randomized open-label crossover study. Diabetes Obes Metab. 2019;21(7):1680-1688.

128. Ranjan A, Schmidt S, Damm-Frydenberg C, Holst JJ, Madsbad S, Nørgaard K. Short-term effects of a low carbohydrate diet on glycaemic variables and cardiovascular risk markers in patients with type 1 diabetes: a randomized open-label crossover trial. Diabetes Obes Metab. 2017;19(10):1479-1484.

129. Dressler A, et al. Type 1 diabetes and epilepsy: efficacy and safety of the ketogenic diet. Epilepsia. 2010;51(6):1086-1089.

130. Eiswirth M, Clark E, Diamond M. Low carbohydrate diet and improved glycaemic control in a patient with type one diabetes. Endocrinol Diabetes Metab Case Rep. 2018;2018:18-0002.

131. Nolan J, Rush A, Kaye J. Glycaemic stability of a cyclist with Type 1 diabetes: $4011 \mathrm{~km}$ in 20 days on a ketogenic diet. Diabet Med. 2019;36(11):1503-1507.

132. Toth C, Clemens Z. Type 1 diabetes mellitus successfully managed with the paleolithic ketogenic diet. Int J Case Rep Images. 2014;5(10):699-703.

133. Turton JL, Raab R, Rooney KB. Low-carbohydrate diets for type 1 diabetes mellitus: a systematic review. PLoS One. 2018;13(3):e0194987.

134. Seckold R, Fisher E, de Bock M, King BR, Smart $\mathrm{CE}$. The ups and downs of low-carbohydrate diets in the management of Type 1 diabetes: a review of clinical outcomes. Diabet Med. 2019;36(3):326-334.

135. Wong KR, Raffray M, Roy-Fleming A, Blunden S, Brazeau AS. The ketogenic diet seen as a normal way of eating by adults with type 1 and type 2 diabetes: a qualitative study [published online ahead of print June 27, 2020]. Can J Diabetes. https:// doi.org/10.1016/j.jcjd.2020.06.016.

136. Davis E, Runyan K. The Ketogenic Diet for Type 1 Diabetes. Gutsy Badger Publishing; 2015.

137. Bernstein RK. Dr. Bernstein's Diabetes Solution: The Complete Guide to Achieving Normal Blood Sugar. Little, Brown and Co.; 2011.

138. Afifi A. From 10 to 5: My Journey With Diabetes. How I Normalized My Blood Sugar. Thoughts About T1, T2 Diabetes Management, Low Carb, Obesity, Fasting, Cholesterol More. 2019.

139. Runyan K. Master Type 1 Diabetes: The Simple, Low-
Cost, Method to Normalize Blood Sugars. 2020. 140.De Beer V. Type 1 and Type 2 Diabetes Cookbook: Low Carb Recipes for the Whole Family. Pavilion; 2017.

141. Choi YJ, Jeon SM, Shin S. Impact of a ketogenic diet on metabolic parameters in patients with obesity or overweight and with or without type 2 diabetes: a meta-analysis of randomized controlled trials. Nutrients. 2020;12(7):E2005.

142.Sainsbury E, Kizirian NV, Partridge SR, Gill T, Colagiuri S, Gibson AA. Effect of dietary carbohydrate restriction on glycemic control in adults with diabetes: a systematic review and meta-analysis. Diabetes Res Clin Pract. 2018;139:239-252.

143. van Zuuren EJ, Fedorowicz Z, Kuijpers T, Pijl H. Effects of low-carbohydrate- compared with low-fat-diet interventions on metabolic control in people with type 2 diabetes: a systematic review including GRADE assessments. Am J Clin Nutr. 2018;108(2):300-331.

144.Huntriss R, Campbell M, Bedwell C. The interpretation and effect of a low-carbohydrate diet in the management of type 2 diabetes: a systematic review and meta-analysis of randomised controlled trials. Eur JClin Nutr. 2018;72(3):311-325.

145. Meng Y, Bai H, Wang S, Li Z, Wang Q, Chen L. Efficacy of low carbohydrate diet for type 2 diabetes mellitus management: a systematic review and meta-analysis of randomized controlled trials. Diabetes Res Clin Pract. 2017;131:124-131.

146.Kirk JK, Graves DE, Craven TE, Lipkin EW, Austin M, Margolis KL. Restricted-carbohydrate diets in patients with type 2 diabetes: a meta-analysis. JAm Diet Assoc. 2008;108(1):91-100.

147. Snorgaard O, Poulsen GM, Andersen HK, Astrup A. Systematic review and meta-analysis of dietary carbohydrate restriction in patients with type 2 diabetes. BMJ Open Diabetes Res Care. 2017;5(1):e000354.

148.van Wyk HJ, Davis RE, Davies JS. A critical review of low-carbohydrate diets in people with Type 2 diabetes. Diabet Med.2016;33(2):148-157.

149. Ludwig DS, Ebbeling CB, Livingston EH. Surgical vs lifestyle treatment for type 2 diabetes. JAMA. 2012;308(10):981-982.

150. Ludwig DS, Ebbeling CB, Heymsfield SB. Improving the quality of dietary research. JAMA. 2019;322(16):1549-1550.

151. Athinarayanan SJ, et al. Long-term effects of a novel continuous remote care intervention including nutritional ketosis for the management of type 2 diabetes: a 2-year non-randomized clinical trial. Front Endocrinol (Lausanne). 2019;10:348.

152. Chen CY, et al. Effect of a $90 \mathrm{~g} /$ day low-carbohydrate diet on glycaemic control, small, dense low-density lipoprotein and carotid intimamedia thickness in type 2 diabetic patients: an 18-month randomised controlled trial. PLoS One. 2020;15(10):e0240158.

153. Weinstock RS, et al. Severe hypoglycemia and diabetic ketoacidosis in adults with type 1 diabetes: results from the T1D Exchange clinic registry. JClin Endocrinol Metab. 2013;98(8):3411-3419.

154.Cengiz E, et al. Severe hypoglycemia and diabetic ketoacidosis among youth with type 1 diabetes in the T1D Exchange clinic registry. Pediatr Diabetes. 2013;14(6):447-454.

155. Cahill GF. Fuel metabolism in starvation. Аnnu
Rev Nutr. 2006;26:1-22.

156. Drenick EJ, Alvarez LC, Tamasi GC, Brickman AS. Resistance to symptomatic insulin reactions after fasting. J Clin Invest. 1972;51(10):2757-2762 .

157. Veneman T, Mitrakou A, Mokan M, Cryer P, Gerich J. Effect of hyperketonemia and hyperlacticacidemia on symptoms, cognitive dysfunction, and counterregulatory hormone responses during hypoglycemia in normal humans. Diabetes. 1994;43(11):1311-1317.

158. Mujica-Parodi LR, et al. Diet modulates brain network stability, a biomarker for brain aging, in young adults. Proc Natl Acad Sci U S A. 2020;117(11):6170-6177.

159. Cahill GF Jr., Aoki TT. Alternate fuel utilization by brain. In: Passonneau JV, Hawkins RA, Lust WD, Welsh FA, eds. Cerebral Metabolism and Neural Function. Williams \& Wilkins: 1980:234-242.

160. Munro JF, Campbell IW, McCuish AC, Duncan LJ. Euglycaemic diabetic ketoacidosis. Br Med J. 1973;2(5866):578-580.

161. Shah P, Isley WL. Ketoacidosis during a low-carbohydrate diet. NEngl JMed.2006;354(1):97-98.

162.Chen TY, Smith W, Rosenstock JL, Lessnau KD. A life-threatening complication of Atkins diet. Lancet. 2006;367(9514):958.

163. Peters AL, Buschur EO, Buse JB, Cohan P, Diner JC, Hirsch IB. Euglycemic diabetic ketoacidosis: a potential complication of treatment with sodium-glucose cotransporter 2 inhibition. Diabetes Care. 2015;38(9):1687-1693.

164. Goldenberg RM, Gilbert JD, Hramiak IM, Woo VC, Zinman B. Sodium-glucose co-transporter inhibitors, their role in type 1 diabetes treatment and a risk mitigation strategy for preventing diabetic ketoacidosis: the STOP DKA Protocol. Diabetes Obes Metab. 2019;21(10):2192-2202.

165. Astrup A, et al. Saturated fats and health: a reassessment and proposal for food-based recommendations: JACC State-of-the-Art Review. JAm Coll Cardiol. 2020;76(7):844-857.

166. Diabetes Control Complications Trial/Epidemiology of Diabetes Interventions Complications (DCCT/EDIC) Research Group. Risk factors for cardiovascular disease in type 1 diabetes. Diabetes. 2016;65(5):1370-1379.

167. de Ferranti SD, et al. Type 1 diabetes mellitus and cardiovascular disease: a scientific statement from the American Heart Association and American Diabetes Association. Diabetes Care. 2014;37(10):2843-2863.

168. Calton JB. Prevalence of micronutrient deficiency in popular diet plans. J Int Soc Sports Nutr. 2010;7:24.

169. de Bock M, et al. Endocrine and metabolic consequences due to restrictive carbohydrate diets in children with type 1 diabetes: an illustrative case series. Pediatr Diabetes. 2018;19(1):129-137.

170. Kossoff EH, et al. Optimal clinical management of children receiving dietary therapies for epilepsy: updated recommendations of the International Ketogenic Diet Study Group. Epilepsia Open. 2018;3(2):175-192.

171. Vining EP, et al. Growth of children on the ketogenic diet. Dev Med Child Neurol. 2002;44(12):796-802.

172. Hannon TS, Rogol AD. Diabetes mellitus and growth in children and adolescents. JPediatr. 
2012;160(6):893-894.

173. Bonfig W, et al. Growth in children and adolescents with type 1 diabetes. J Pediatr. 2012;160(6):900-3.e2.

174. Fröhlich-Reiterer EE, et al. Anthropometry, metabolic control, and follow-up in children and adolescents with type 1 diabetes mellitus and biopsy-proven celiac disease. J Pediatr. 2011;158(4):589-593.e2.

175. Gallagher KAS, DeSalvo D, Gregory J, Hilliard ME. Medical and psychological considerations for carbohydrate-restricted diets in youth with type 1 diabetes. Curr Diab Rep. 2019;19(6):27.

176. Cefalu WT, et al. Insulin Access and Affordability Working Group: conclusions and recommendations. Diabetes Care. 2018;41(6):1299-1311.

177. Roberts DK. The deadly costs of insulin. Am J Manag Care. Published June 10, 2019. https:// www.ajmc.com/view/the-deadly-costs-of-insulin.

178. [No authors listed]. National diabetes statistics report, 2020. Centers for Disease Control and Prevention. https://www.cdc.gov/diabetes/ library/features/diabetes-stat-report.html. Accessed November 11, 2020.

179. American Diabetes Association. Economic costs of diabetes in the U.S. in 2017. Diabetes Care. 2018;41(5):917-928.

180. Donaghue KC, et al. Beneficial effects of increasing monounsaturated fat intake in adolescents with type 1 diabetes. Diabetes Res Clin Pract. 2000;48(3):193-199.

181. Soedamah-Muthu SS, Chaturvedi N, Fuller JH, Toeller M, EURODIAB Prospective Complications Study Group. Do European people with type 1 diabetes consume a high atherogenic diet? 7-year follow-up of the EURODIAB
Prospective Complications Study. Eur J Nutr. 2013;52(7):1701-1710.

182. Strychar I, et al. Effects of a diet higher in carbohydrate/lower in fat versus lower in carbohydrate/higher in monounsaturated fat on postmeal triglyceride concentrations and other cardiovascular risk factors in type 1 diabetes. Diabetes Care. 2009;32(9):1597-1599.

183. Chantelau EA, Frenzen A, Gösseringer G, Hansen I, Berger M. Intensive insulin therapy justifies simplification of the diabetes diet: a prospective study in insulin-dependent diabetic patients. Am J Clin Nutr. 1987;45(5):958-962.

184. Knight BA, Hickman IJ, Gibbons K, McIntyre HD. Quantitative assessment of dietary intake in adults with Type 1 diabetes following flexible insulin therapy education with an active promotion of dietary freedom. Diabetes Res Clin Pract. 2016;116:36-42.

185. Chantelau E, Sonnenberg GE, Stanitzek-Schmidt I, Best F, Altenähr H, Berger M. Diet liberalization and metabolic control in type I diabetic outpatients treated by continuous subcutaneous insulin infusion. Diabetes Care. 1982;5(6):612-616.

186. Nielsen JV, Jönsson E, Ivarsson A. A low carbohydrate diet in type 1 diabetes: clinical experience-a brief report. Ups JMed Sci. 2005;110(3):267-273.

187. Nielsen JV, Gando C, Joensson E, Paulsson C. Low carbohydrate diet in type 1 diabetes, longterm improvement and adherence: a clinical audit. Diabetol Metab Syndr. 2012;4(1):23.

188. Bouillet B, Rouland A, Petit JM, Vergès B. A low-carbohydrate high-fat diet initiated promptly after diagnosis provides clinical remission in three patients with type 1 diabetes. Diabetes
Metab. 2020;46(6):511-513

189. McClean AM, Montorio L, McLaughlin D, McGovern S, Flanagan N. Can a ketogenic diet be safely used to improve glycaemic control in a child with type 1 diabetes? Arch Dis Child. 2019;104(5):501-504.

190.Vernon MC, Mavropoulos J, Transue M, Yancy WS, Westman EC. Clinical experience of a carbohydrate-restricted diet: effect on diabetes mellitus. Metab Syndr Relat Disord. 2003;1(3):233-237.

191. O'Neill DF, Westman EC, Bernstein RK. The effects of a low-carbohydrate regimen on glycemic control and serum lipids in diabetes mellitus. Metab Syndr Relat Disord. 2003;1(4):291-298.

192.de Souza Bosco Paiva C, Lima MHM. Introducing a very low carbohydrate diet for a child with type 1 diabetes. Br J Nurs. 2019;28(15):1015-1019.

193. Leow ZZX, Guelfi KJ, Davis EA, Jones TW, Fournier PA. The glycaemic benefits of a very-low-carbohydrate ketogenic diet in adults with Type 1 diabetes mellitus may be opposed by increased hypoglycaemia risk and dyslipidaemia. Diabet Med. 2018;35(9):1258-1263.

194. Bernstein RK. Virtually continuous euglycemia for $5 \mathrm{yr}$ in a labile juvenile-onset diabetic patient under noninvasive closed-loop control. Diabetes Care. 1980;3(1):140-143.

195. Henwood MJ, Thornton PS, Preis CM, Chee C, Grimberg A. Reconciling diabetes management and the ketogenic diet in a child with pyruvate dehydrogenase deficiency. J Child Neurol. 2006;21(5):436-439.

196. Tóth C, Clemens Z. A child with type 1 diabetes mellitus (T1DM) successfully treated with the Paleolithic ketogenic diet: a 19-month insulin freedom. Int J Case Rep Images. 2015;6(12):753-758 